College, by whom it was clinically diagnosed as "undoubtedly a case of scurvy." The patient was a Hindu, aged 25 years. He was admitted into the hospital on Jan. 24th, 1901, complaining of general debility accompanied by swelling of the left foot and leg and bleeding from the gums. He was a man from the bazaar and any accuunt of his dietary was in consequence not trustworthy. He said, however, that he regularly ate vegetables although his staple diet was bread made of bajari flour and a mess of pulse. He had been ill with the symptoms he then complained of for about three weeks before admission to the hospital. He came under my observation on the 26th-viz., two days after admission. His condition then was as follows $\mathrm{He}$ was markedly breathless on exertion. The face was bloated and sallow. The gums were much swollen, very spongy, red, and detached from the teeth, pro. jecting beyond them in loose bluish-red masses which were very painful and bled on the slightest touch. The detachment from the teeth was best marked along the inner aspect of the gums. The breath was very foetid. There was considerable cedema of the left leg and foot and also of the lower third of the thigh. Associated with this there were tense, brawny, indurated swellings of the muscles of the calf, in front of the tibia, and in the popliteal space. There was no diarrhoea or purpuric eruption. The blood coagulation time was found to be two and a half minutes. The red cells numbered 4,000,000 per cubic millimetre. The alkalinity of the blood serum was $\frac{N}{30}$. The patient was given the ordinary Hindu diet of rice and vegetables. In addition he was given both fresh limes and lime-juice along with a little quinine. He was discharged on March 2nd. On that date it was noted that the swelling of the legs was much less and that there was still slight puffiness below the left patella. The gums were normal.

CASE 11.-This case also was under the care of Major Lyons. The patient was a Hindu, aged 35 years. He was admitted into the hospital on Feb. 22nd, 1901, complaining of painful swelling of both knee-joints and of swelling and bleeding of the gums. He said that he had been ill for ahnut three weeks. He came under my observation on the 24th. when he was found to be thin and anæmic. His face was swollen, with a sallow and bloated appearance. The gums were swollen, spongy, painful, and markedly detached from the teeth, and they bled readily on being touched. There were several small petechiæ of a brownish colour over the thighs. These were not raised above the surface of the skin. Both knee-joints were swollen and paintul, the pain extending up the thighs and into the loins. There was no cedema of the feet and legs, nor were there any extravasations between the muscles. There was a small, painful, subperiosteal swelling over the anterior surface of the upper third of the left tibia. The bowels were constipated. There had been no external bleeding since the onset of the illness. The blood coagulation time was found to be three and three-quarter minutes, while the alkalinity of the blood serum was estimated as $\frac{N}{30}$. The treatment employed in this case was the same as was used in Case 10. The patient was discharged from hospital on April $23 \mathrm{rd}$ when it was observed that the gums were healthy in aprearance and that the pains in the joints had disappeared. There was still slight numbness present in the feet when attempts at walking were made.

Thi- then. completes the record of the cases of scurvy which have come under my direct observation. The whole of the fact: brought forward go to show that the condition present in these cases was not a condition of acid intoxication In view of Professor Wright's observations the only concluiiun. therefore, which I can come to is that scorbutic sym toms, although associated in some cases-viz., in Profes:or Wright's ca-es-with a condition of acid intoxication, in other case- develıp quite independently of this condition. There wnuld seem, in fact, more than one etiological factor and pathol gical condition underlying the symptoms which are clinically known as scurvy.

In cinclusion, it is only necessary to point out that my obrervarions, both of the series of cases in the Thana Jail and of the -eries in the Jamsetjee Jeejeebhoy Hospital, lend $\mathrm{n} n: 11, \ldots, \mathrm{lt}_{\mathrm{t}}$ to the theory advanced by Lieutenant Listonviz., that -curvy symutoms may merely be an expression of anky intrmiasis.

\section{ABDOMINAL PAN-HYSTERECTOMY FOR CANCER OF THE UTERUS ; WITH NOTES OF TWO CASES.}

By ARTHUR H. N. LEWERS, M.D., F.R.C.P. LoNd., OBSTETRIC PHYSICIAN TO THE LONDON HOSPITAL.

IN cases of cancer of the uterus which come under observation at a time when operative treatment of a radical nature is indicated, there can be no doubt that, for the large majority, the vaginal route is the most suitable for the removal of the 'uterus. As regards cancer of the cervix almost all the advantages appear to be on the side of vaginal hysterectomy. Thus in the latter operation the exact position and extent of the growth are clearly visible, and the incisions in the vaginal mucous membrane can be made as far as possible from the edge of the growth. Another advantage, which I myself believe to be of some importance, is that the cut edges of the vaginal mucous membrane and the adjacent submucous connective tissue can, in vaginal hysterectomy, be freely seared with the cautery. Apart from some coincident pathological condition-such as fibroids-the body of the uterus is not enlarged in cancer of the cervix, so that in vaginal hysterectomy there is usually no difficulty in removing the body of the uterus on account of its size. Again, there is, as a rule, less general disturbance after vaginal hysterectomy-less tendency to-vomiting, distension, rapid pulse, and less pain-than in operations involving opening the abdomen in the usual position. In a purely abdominal pan-hysterectomy for cancer of the cervix the vagina has, of course, to be opened into from above, and the incision may or may not clear the malignant growth. Some cortion of it is almost certain to be left behind, and the operation thereby rendered useless. It is true that this objection may be met by performing a combined operation, partly from below, freeing the cervix as in the first stage of a vaginal hysterectomy, and then completing the operation from above. This procedure will, I think, be generally admitted to be at least inconvenient, owing to the loss of time in altering the position of the patient, and having again to go through the processes for disinfecting the hands prior to opening the abdomen. At least, this has seemed so to me in the few cases, some of them in operations for uterine fibroids, in which $I$ adopted it. Again, in abdominal hysterectomy it is far easier to remove the upper portion of the broad ligaments with the tubes and ovaries than when the operation is performed from below, but in cancer of the cervix this is a matter of little or no importance, since the disease has no tendency to spread in the direction in question, at all events at a stage of the disease when hysterectomy is likely to be performed. Another point is that if ligatures are used to secure the vessels, these can, as a rule, be tied much more securely in abdominal than in vaginal hysterectomy. Still, as a matter of experience, there is rarely any difticulty in sufficiently securing the vessels in the latter operation, either by ligatures or pressure forceps.

There is one more question to be thought of in considering the operation to be chosen in cases of eancer of the cervix. I refer to the infection of the lymphatic glands. If it were the fact, as is maintained by some authorities, that the glands are always, or generally, affected in those cases of cancer of the cervix in which, as far as physical examination can ascertain, the disease has not spread beyond the limits of the uterus, no operation would be satisfactory by which these glands were not removed, and hence abdominal hysterectomy with removal of the glands would have to be the routine operation in all cases of cancer of the uterus, whether of the cervix or of the body, when any radical operation was to be done at all. But it is certainly not the fact that the glands are always affected at a stage of the disease when hysterectomy would be contemplated, nor do I believe it to be anything but a very infrequent occurrence at the stage of the disease in question. The proof of this lies in the after-histories of cases operated on for cancer of the uterus in which the glands have not been removed. Among my own cases I have recorded a series of 40 vaginal hysterectomies for cancer in the Transactions of the Royal Medical and Chirurgical Society of London. The specimens, and sections of them, were shown at the meeting at which 
the admitted. Yet among them I was able to point to 12 cases out of 40 in which the after-history of the patient was known and in which the disease had not recurred. Two of these remained well seven years after the operation, one six years, one five and a half years, one five years, one nearly five years, one nearly four years, one more than three years, two nearly three years, one more than two years, and one more than one year. I may instance also several cases from an earlier series of operations for cancer of the cervix in which I merely performed the supra-vaginal amputation of the cervix. Some of the patients were known to be well many vears after the operation. In each case the specimen and sections were exhibited at the meeting of the Royal Medical and Chirurgical Society at which the paper recording the cases was read, so that there can be no doubt as to the disease being cancer. It is clear that the after-histories of these cases sufficiently prove that the glands are not by any means always affected in cases of cancer of the uterus at an operable stage. My own belief is that when the glands are affected the disease has usually already advanced beyond the limits of the uterus, either to the vagina or connective tissue round the cervix, and any operation having for its object the cure of the disease, or even prolonged freedom from recurrence, is already ipso facto contra-indicated. We may therefore conclude that for cases of cancer of the cervix requiring removal of the uterus the operation of election should be vaginal hysterectomy.

When, however, we come to consider cases of primary cancer of the body of the uterus we are on much more debateable ground. In cancer of the body of the uterus the cervix, and especially the vaginal portion of the cervix, is generally altogether unaffected. At times in rare instances the malignant growth has spread a variable distance down the cervical canal, and it may even show at the external os uteri. This is a very rare event, and even when it occurs the onter surface of the vaginal portion is not involved. Hence in performing abdominal pan-hysterectomy, when the vagina is opened into from above, so long as the incisions clear the cervix-and it is a matter of no particular difficulty to make sure of this-there is no risk of leaving some of the malignant growth behind. Again, the body of the uterus is considerably enlarged, and on the other hand, as the subjects of this disease are for the most part elderly women between 50 and 60 years or older, the vagina is narrow from the contraction due to the senile atrophy occurring after the menopause. As many of the patients are sterile the vagina has, even before the menopause, not been dilated to the capacity found in parous women. Both on account of the size of the uterus and of the narrowness of the vagina removal of the uterus from below is a more difficult matter than from above. In abdominal hysterectomy, also, the fact that it is an easy matter to remove the ovaries and tubes with a good width of the upper part of the broad ligament on each side of the uterus is, in primary cancer of the body, a distinct advantage. An objection to the abdominal route deserving mention is the risk of fouling the peritoneum with the discharge escaping from the os uteri as the uterus is brought upwards. This may, however, be avoided by passing a stout ligature through the vaginal portion of the cervix so as to encircle the os, and tying it tightly.

One more important question is the relative mortality of the two operations. Soon after Czerny had re-introduced vaginal hysterectomy in 1879 Freund began to remove the uterus by abdominal section. The mortality, as is stated in Greig Smith's work on Abdominal Surgery, was nearly 70 per cent. The mortality of vaginal hysterectomy for cancer about the same time or within the next five years was nearly 30 per cent Thus the abdominal method, being so much the more dangerous, gradually fell into complete disuse, and for some years vaginal hysterectomy alone was practised. Though the operation for cancer had been abandoned, the technique of abdominal hysterectomy for fibroids continued to receive the closest attention from many operators. In this way were evolved the two operations for fibroids now in favour-first, abdominal hysterectomy with intra-peritoneal treatment of the cervical stump, the essential point in the operation being the ligature of the uterine arteries ontside uterine tissue; and next abdominal pan-hysterectomy, or removal of the whole uterus by an operation conducted entirely from above. Both these operations have now a very low mortality, probably not exceeding 5 per cent. I was led to perform abdominal panhysterectomy for fibroids by reading Martin's paper in the
Transactions of the Edinburgh Obstetrical Socicty for 1896 , and I have adopted it in five cases, all of which have made uneventful recoveries, though in most of my hysterectomies for fibroids I have been quite content with abdominal hysterectomy with intra-peritoneal treatment of the stump. Of course, it must not be forgotten that during the period in question the mortality of vaginal hysterectomy for cancer has also been greatly reduced. In my own series of 40 cases, already referred to, the mortality, for instance, was $7 \frac{1}{2}$ per cent. It is probably not far from the truth to say that at the present time, in the case of an operator who has had experience in both operations, there is not much difference in the mortality of abdominal pan-hysterectomy and vaginal hysterectomy for cancer. On the whole, therefore, it seems to me that, for cancer of the body of the uterus, abdominal pan-hysterectomy has in many cases preponderating advantages.

Although, as above mentioned, I have performed abdominal pan-hysterectomy for fibroids I have as yet only performed the operation for cancer of the body of the uterus in two cases, the notes of which are as follows.

CASE 1.-A woman, aged 54 years, came to see me on Feb. 12th, 1900. She had been married for 15 years but had never been pregnant. She had been quite regular up to the age of 50 years, when she had synovitis, and stayed in bed for some time, after which menstruation ceased altogether. In July, 1899, she began to have some vaginal dis. charge. It was at first colourless, but afterwards sometimes yellow and sometimes of a brown colour, and continued up to the time I saw her. She had no pain at all, and did not think that she had lost weight. The discharge had at times had an unpleasant smell. There was nothing else in the history of any special interest. Nothing abnormal was detected on examining the abdomen. On vaginal examination the external genitals were redder than normal and slightly sore-looking, and there was some yellow discharge at the vaginal orifice. The vagina was extremely narrow and examination with one finger caused

FIG. 1.

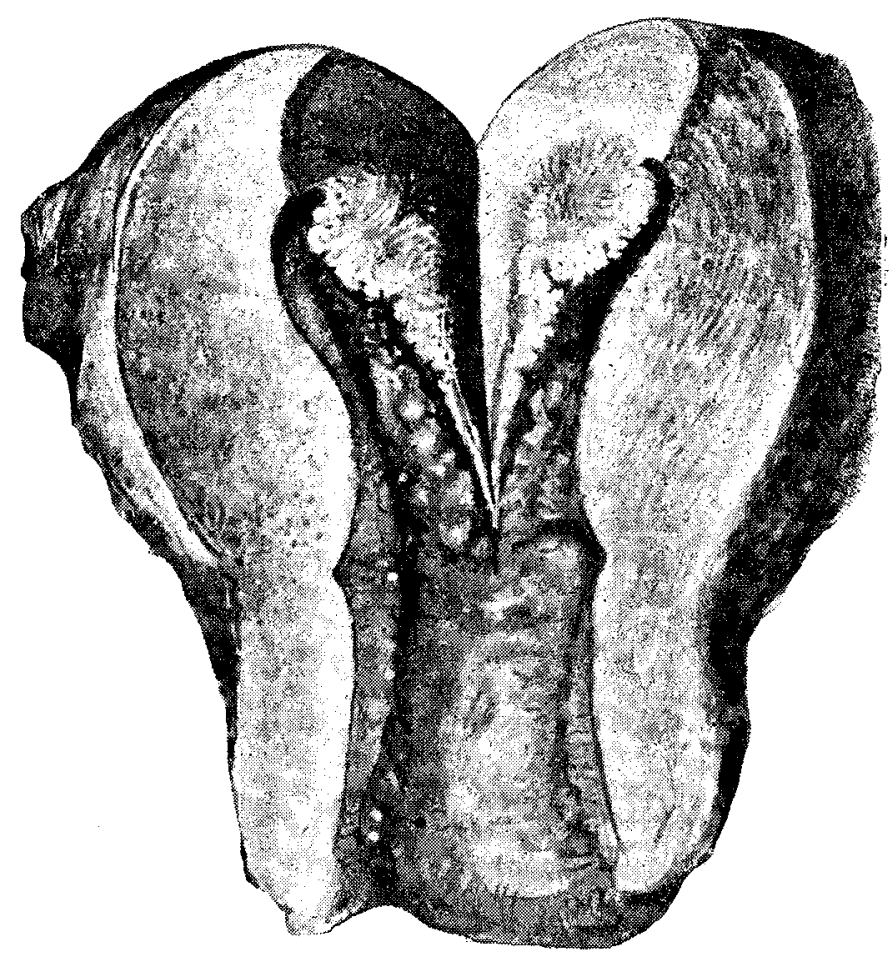

The uterus removed in Case 1. It has been laid open by a longitudinal incision through the anterior wall. The growth is seen springing from the posterior surface of the endometrium near the fundus. An incision has also been marde through the upper part of the posterior wall of the uterus. On the cut surface the decper portion of the growth is seen penetrating the uterine tissue. This specimen llustrates carcinoma of the body of the uterus at an earlier stage than in any other 1 have seen. The meeting of the Obstetrical Society of London on Jan 1st.)

a good deal of discomfort. On this account the examination was not very satisfactory, but, as far as could be made out, the uterus was freely moveable, and the external os was rather small. There was nothing abnormal as regards the vaginal portion of the cervix. 'The extreme narrowness of the vagina was shown by the fact that the patient could not bear the smallest Fergusson's speculum to be passed. A. 
small rectal speculum was, however, passed into the vagina, but, as it was rather less than half the length of an ordinary Fergusson's speculum. it only showed the lower two inches of the vaginal walls, which were thinly covered with the yellow discharge above mentioned. I advised the patient to have the cervix dilated sufficiently to allow the interior of the body of the uterus to be examined with the finger. She consented to have this done, but as she wished to return to the north of England for a fortnight it was not till March 1st that she entered Fitzroy House. The next day, with the usual antiseptic precautions, a specially prepared laminaria tent was inserted into the cervix. To do this, owing to the narrowness of the vagina, it was necessary to have the patient anæsthetised. Speaking from memory, I believe I have only once before found it necessary to have the patient anæsthetised for the insertion of tents, so that it will be seen that the narrowness of the vagina was such as to cause real difficulty in dealing with the case. On March 3rd the dilatation of the cervix was completed under an anæsthetic with Hegar's dilators. A growth was found high up in the endometrium. A portion of it was removed for microscopical examination, though I felt little doubt after the digital examination of the endometrium that the growth was malignant. The portion of growth removed was sent to the Clinical Research Association and Mr. J. H. Targett reported that it was carcinomatous. The patient was accordingly advised to have the uterus removed, and to this she consented.

The operation was performed on April 11th. The preliminary dilatation of the cervix for diagnosis had been so difficult on account of the narrowness of the vagina that I decided to remove the uterus by abdominal pan-hysterectomy. The method was the same as that adopted in four cases of pan hysterectomy for fibroids, an account of which has already been published. ${ }^{1}$ In this case the vagina was douched with a solution of perchloride of mercury ( 1 in 1000) just before the operation, but I did not make any attempt to occlude the cervix by a suture, or to pack it before beginning the abdominal section. The right uterine appendages were removed with the uterus, but the left appendages were not removed. The ligatures on the uterine arteries and on vessels in the cut edges of the vaginal walls were left long and drawn down into the vagina by long Wells's forceps passed up from the vagina by an assistant. A gauze drain was drawn down from above into the vagina, about an inch of it being left projecting into the peritoneum. The abdominal wound was completely closed. The patient made an uninterrupted recovery, and the ligatures came away at the end of the fifth week.

The following is a description of the specimen: "The uterus has been laid open by an incision from the external os to the fundus through the anterior wall. The extreme length of the uterus is three inches. At the extreme highest point of the endometrium, and extending downwards for an inch and a quarter on the posterior wall, is a new growth projecting only slightly above the general surface of the endometrium. Its surface is faintly papillary. A sagittal section has also been made through the growth and the wall of the uterus from which it springs. This shows that the growth penetrates deeply into the uterine wall, the limit of its penetration, to the naked eye, being marked by a sinuous, irregular, whitish border." A portion of the growth was sent to the Clinical Research Association and Mr. Targett reported on it as follows: "The wall of the uterus is deeply invaded by a very soft columnar-celled carcinoma. The growth is much degenerated and therefore stains badly. It is a primary carcinoma of the body of the uterus."

CASE 2. - A woman, aged 57 years, was admitted under my care into the London Hospital on Oct. 5th, 1901, at the request of Dr. W. C. Taylor of Victoria Dock-road, London, E. She had been married for 36 years, and had had six children, the last 21 years ago, and two miscarriages, the last 19 years ago. Menstruation began when she was between 16 and 17 years of age and occurred regularly every four weeks without any pain. Two and a half years ago menstruation ceased for 10 months. Then the periods came on for three months at monthly intervals. Each of these periods was like what she had always had except that she lost a larger quantity than formerly and clots were passed. She had been subject to bronchitis and asthma up to last year; she used to have quinsy 20 years ago. There was no bistory of syphilis, nor had she ever had any severe illness. Her family history was good. Two and a half years ago the periods ceased for 10 months, then they recurred three times at monthly intervals; after that, however, the loss of blood became more or less continuous. Sometimes clots were passed, but the discharge was never offensive. The discharge during the previous three months had not been quite so profuse as before, but she had had constantly

FIG. 2.

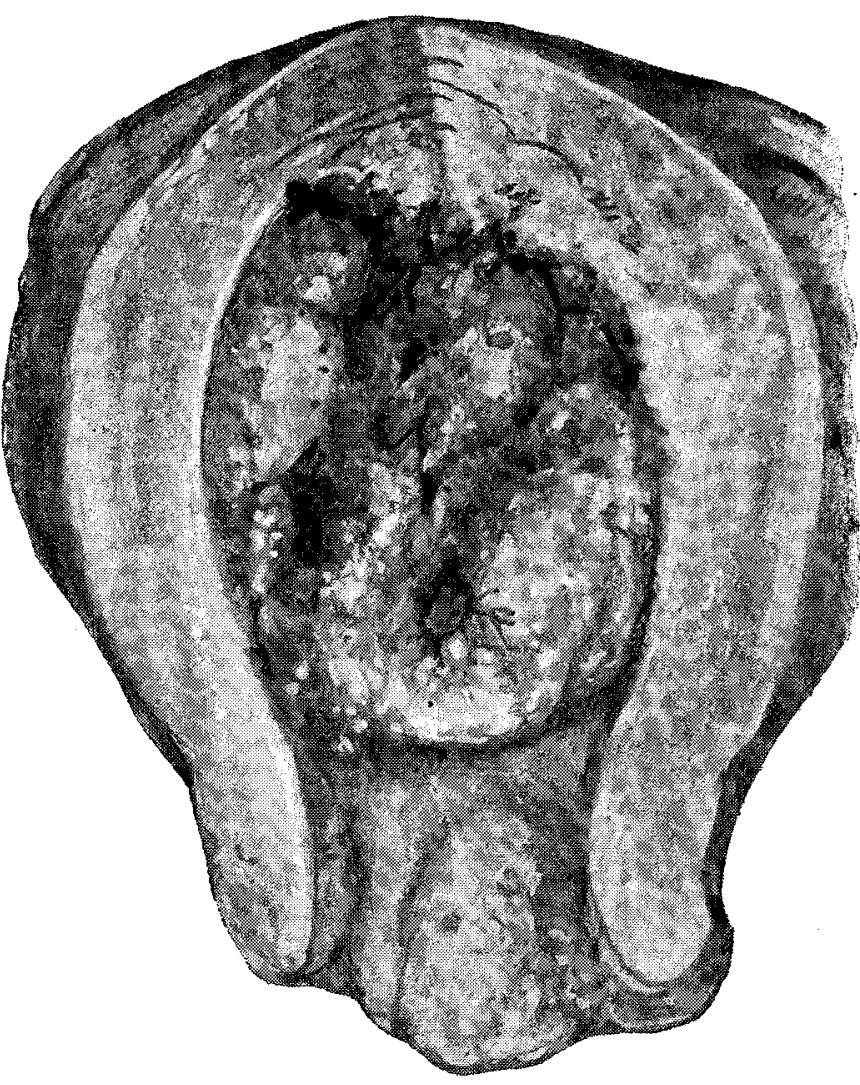

The uterus removed in Case 2 and laid open by an incision through the anterior wall. The malignant growth occupies hearly all the endometrium and terminates below by raised border slichtly etrium and terminates below by a rorth noticing that, contrary to the the internal os. It is patent frome in similar cases, the patent from whom this specimen was removed had theen pregnant 8 times. (Ihe specimen was shown at the meeting of the Obstetrical Society of London
on Jan. 1st.)

to wear a diaper. Since April she had had pain on the right side running from the back to the right groin, and also aching in the right thigh. It was not constant, for sometimes she would be free from pain for 12 hours. When present it was aching, with an occasional severe shooting or cramping feeling. Sometimes the pain made her sick, and caused her to perspire, especially at night. It was relieved by sitting up or by walking about, and sometimes by alcohol. She had had no trouble with micturition, but the bowels had been constipated and she took aperients frequently. During the eight months before admission she had lost two stones in weight. From the above account it appears that there had been more or less constant blood-stained discharge for about 17 months and that she had had pain for six months prior to her admission to the hospital. On admission she was found not to be anæmic. She had a rather worried expression. Her weight was nine stones two pounds. On the 7 th she was anæsthetised and a careful examination was made with the patient in the lithotomy position. With Sims's speculum it was seen that the vaginal portion of the cervix was healthy except for a slight erosion on the posterior lip. The cervix when drawn upon with a volsella did not come down well. Bimanually the nterus was found to be enlarged, but only fairly moveable ; the sound passed three and a half inches. The cervix was dilated up to Hegar's dilator No. 19 without any difficulty, there being only slight resistance as each dilator was passed, and that at the external os. The finger passed into the uterus came upon a growth, chiefly on the posterior wall ; it was not of the soft papillary variety. It terminated below by a raised, somewhat rounded border. The growth extended so low in the body of the uterus that it was not quite certain at this examination that the growth had not extended into the cervical canal. (Subsequent examination of the specimen, however, showed that it had not involved 
the cervix.) There was no offensive smell about the examining finger.

The operation was performed on the 14th. The patient was anæsthetised and put in the lithotomy position. After disinfecting the vagina as well as possible with a lotion of perchloride of mercury ( 1 in 1000) the cervix was exposed and seized with a volsella. A stout silk ligature was passed through the vaginal portion with a strong needle in a handle from behind forwards on the left side of the os uteri. The needle, unthreaded, was then passed similarly on the right side of the 0 , threaded with the anterior end of the ligature already passed, and withdrawn. The ligature was then tied as tightly as possible, thus occluding the external os. The patient was then put into the Trendelenburg position and abdominal pan-hysterectomy was performed. The right uterine appendages were removed, but the left appendages were allowed to remain. There were some adhesions on the left side which had to be separated before the uterus could be drawn out freely The limited mobility of the uterus observed at the previous examination was no doubt due to these adhesions. When the uterus had been removed all the ligatures were drawn into the vagina and a strip of iodoform gauze was also drawn into the vagina. About one inch of it was left projecting into the peritoneal cavity. The abdominal wound was then completely closed. The subsequent progress of the case was uneventful. The ligatures were not loose when she left the hospital; they were cut a good deal shorter a few days before she went away, so that it would be impossible for any of them to project from the vagina. She went to a convalescent home on Nov. 9th.

The following is a description of the specimen: "The uterus has been laid open from the front. Its extreme length is three and three-quarter inches. The cervix to the naked eye appears quite healthy, and is very short. Almost the whole of the endometrium is occupied by a new growth ; this is raised about a quarter of an inch above the general level and its edge distinctly overhangs the adjacent apparently healthy endometrium. In the downward direction the growth extends very nearly to the internal os and terminates by a semicircular border convex downwards." A portion of the growth was sent to the Clinical Research Association and Mr. Targett reported on it as follows: "This is a columnar-celled carcinoma of the body of the uterus originating in the endometrium and invading the muscular coat. The tubular arrangement of the cells is very distinct." Harley-street, W.

\section{ON TWO CONTRASTED CASES OF'HYSTER- ECTOMY: ONE DURING PREGNANCY, THE OTHER IN PUERPERY.}

By J. BLAND-SUTTON, F.R.C.S. ENG., ASSISTANT SURGEON TO THE MIDDLESEX HOSPITAL.

ON August 28th, 1901, at the Middlesex Hospital I performed abdominal hysterectomy on two patients for conditions in regard to the proper treatment of which gynæcologists and obstetricians hold anything but unanimous opinions. The two cases stand in striking contrast, for in Case 1 the operation was undertaken with the view of averting a dangerous condition which had actually supervened in Case 2, and not only placed the patient's life in the gravest peril but surrounded the operation and the convalescence with great danger.

CASE 1.-A well-developed woman, 28 years of age, sought advice for an abdominal swelling which, she said, had recently grown much larger and had become painful. On careful inquiry we elicited two very important factsfirst, that her menstruation, never profuse, had been in abeyance three months. On examination a hard rounded swelling as big as a fist occupied the right iliac fossa : a larger rounded tumour could be felt immoveably impacted in the pelvis to the left of the cervix, whilst the vaginal portion of the cervix was pushed to the left side, and in order to reach it the finger had to sweep over the rounded contour of the impacted tumour which appeared to usurp all the arailable space in the true pelvis. Pressure on the tumour caused pain and there was some difficulty with the rectum, but fortunately there was no interference with the bladder.
The nature of the case was very clear-namely, fibroids impacted by pregnancy. So firmly was the tumour incarcerated that $I$ had no hesitation in recommending the patient to submit to operation. I was very careful to explain to the class the reason for this advice. When the uterus is distorted by fibroids and so much displaced as in this case abortion is sure to occur ; the damage to the fibroid which is inevitable in such circumstances would place the patient's life in the gravest peril if she should become septic. Even apart from this risk we now realise that pregnancy in itself leads to some little-understood changes in fibroids quite apart from septic infection. In deciding the question of pregnancy I was careful to point out that there were no physical facts to guide me, but I relied on the three months' amenorrhoa in a buxom woman, her statement that the tumour had lately very markedly increased in size, and the firmness of the impaction.

At the operation the uterus was found to be more displaced than had been anticipated. A large tumour in the anterior wall was impacted in the pelvis, the gravid uterine body was situated in the hypogastrium, and the tumour in the posterior wall of the uterus occupied the right iliac fossa, so that the uterus was not only rotated through $90^{\circ}$, but also acutely flexed. I performed supra-vaginal hysterectomy and left both ovaries and Fallopian tubes, as they appeared healthy. The patient made a quick and satisfactory convalescence.

The uterus with the tumours was carefully hardened and then sectioned in a sagittal direction (see Figure). It

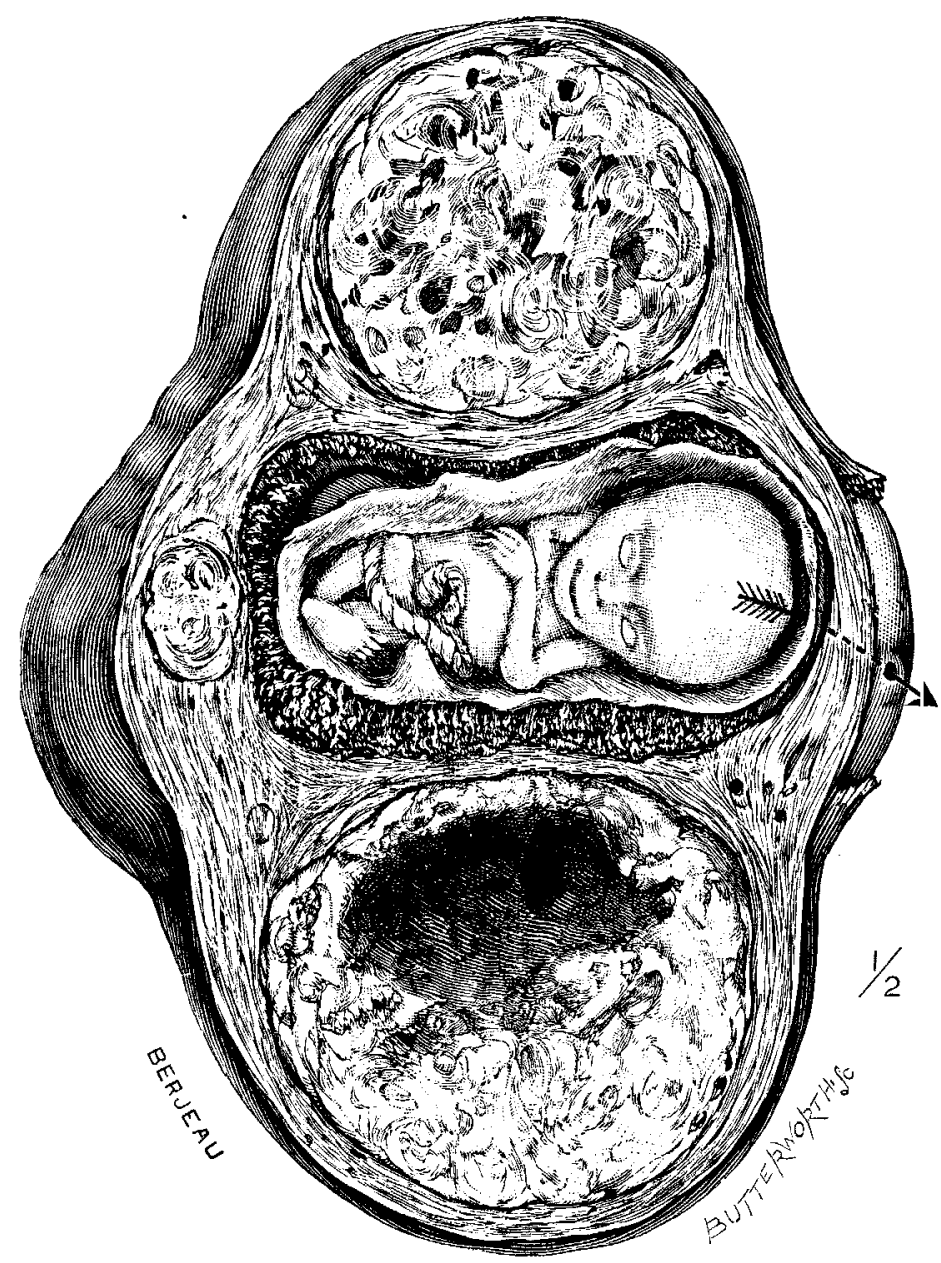

A gravid uterus shown in section; it is deformed by fibroids. Removed from a woman 28 years of age. The arrow lies in the cervical canal.

measured in its antero-posterior (sagittal) axis 20 centimetres after it had been hardened and as the conjugate diameter of the pelvis is at most 10 centimetres it is clear that a great amount of rotation had slowly taken place to allow the parts to accommodate themselves in the pelvis. I have already drawn attention in THY LANCET ${ }^{l}$ to a very similar case. The tumours in this specimen on section exhibited irregular dark red streaks: they were most marked in the larger tumour which had in addition undergone myxomatous changes and its central portion was diffluent.

CASE 2.-This patient was a married woman, 36 years of age. In 1896 she had been deliverert of a healthy child. Two years later a fibroid of the size of a turkey's egg was

1 The Lancer', Feb. 16th, 1901, p. 452. 